\title{
Effect of Heating Methods on Quality Attributes of Culled Saanen Crossbred Goat Meat
}

\author{
Aronal Arief PUTRA ${ }^{1,3}$, Saowakon WATTANACHANT ${ }^{1, *}$ and \\ Chaiyawan WATTANACHANT ${ }^{2}$
}

\author{
${ }^{1}$ Department of Food Technology, Faculty of Agro-Industry, Prince of Songkla University, \\ Songkhla 90112, Thailand \\ ${ }^{2}$ Department of Animal Science, Faculty of Natural Resources, Prince of Songkla University, \\ Songkhla 90112, Thailand \\ ${ }^{3}$ Division of Technology of Animal Products, Faculty of Animal Science, Universitas Andalas, \\ Padang 25163, Indonesia
}

("Corresponding author's e-mail: saowakon.w@psu.ac.th)

Received: 1 December 2016, Revised: 19 July 2017, Accepted: 8 August 2017

\begin{abstract}
The effect of boiling, grilling, and microwaving until reaching temperature of $85{ }^{\circ} \mathrm{C}$ on culled Saanen goat meat was evaluated and compared to raw samples. Biceps femoris muscle was used to evaluate the effect of these heating methods on proximate composition, collagen, cook loss, color, and texture profile analysis. Supraspinatus muscle was used to determine the effect of these heating methods on changes in peroxide value (PV) and thiobarbituric acid reactive substances (TBARS) of meat during 5 days of chilled storage. Boiled and grilled samples showed lower moisture (63.04 and $63.89 \%$, respectively) and higher protein (29.20 and 29.59\%, respectively) and fat (5.98 and 4.01\%, respectively) than those of the microwaved sample $(68.03 \%$ moisture, $26.72 \%$ protein, and $2.95 \%$ fat $)(\mathrm{P}<0.05)$. Higher total collagen in the grilled sample $(14.35 \mathrm{mg} / \mathrm{g})$ and higher soluble collagen percentage $(6.57 \%)$ in the microwaved sample were obtained $(\mathrm{P}<0.05)$. Boiled and grilled samples revealed higher cook loss (39.70 and $41.28 \%$, respectively) compared to microwaved samples $(28.82 \%)(\mathrm{P}<0.05)$. Grilled samples exhibited higher hardness $(3,730.21 \mathrm{~g})$, gumminess $(2,397.76)$, and chewiness $(1,774.71)$ than those of other heated samples $(\mathrm{P}<0.05)$. Higher lightness $\left(\mathrm{L}^{*}=54.90\right)$, lower redness $\left(\mathrm{a}^{*}=4.11\right)$ and yellowness $\left(b^{*}=13.96\right)$ in boiled sample were found $(\mathrm{P}<0.05)$. Grilled samples exhibited sharper PV formation while boiled samples revealed sharper TBARS formation during storage $(\mathrm{P}<0.05)$. In summary, variation in remaining moisture, soluble collagen, parallel with types of heating medium led to complexity in the results obtained in total solid, cook loss, color, and texture profile analysis (TPA). Boiled samples were prone to yield higher TBARS formation.
\end{abstract}

Keywords: Culled Saanen goat, meat quality, heating method, muscle structure, lipid oxidation

\section{Introduction}

Saanen goat is a popular dairy breed widely distributed worldwide due to its good milk production. Culled Saanen goat is also an alternative goat meat. However, the utilization of meat from dairy is very limited due to its tough texture attributes. This is associated with higher collagen crosslinking in older animals. This problem leads to more limited kinds of product which could be prepared. Thus, it is important to find suitable cooking methods to increase rupture in collagen crosslinking.

Selection of a suitable cooking method for meat cookery might be decided by considering type, connective tissue content, or dimension of meat prepared for cooking. Thus, various cooking methods are 
http://wjst.wu.ac.th

widely found and developed in moist-, dry-, and electromagnetic-type cooking [1]. Moreover, boiling, grilling, and microwaving are 3 common domestic cooking methods. Related to goat meat cookery, the source of availability in the market is from yearling goat. Generally, it is cooked in the form of curry. The basic principle of curry cookery is heating the meat in boiled water, while the ingredients might be varied among countries.

Thermal processing is mostly conducted for meat products manufacturing and household cooking. Sufficient heating results in changes in the meat from unpalatable to an edible and digestible states. Generally, the changes obtained in finished products can be seen from their textural hardening/softening, moisture loss, fat melting, structural shrinkage, browning development, and specific cooked aroma and oxidation product formation. Moreover, quality properties of cooked meat might widely vary depending on the thermal approach applied. It might be associated with end point temperature [2], cooking rate and holding time [3], temperature and time [4], or cooking method [5].

Some researchers have evaluated the effect of various cooking methods on meat from small ruminants [6-9]. However, to our knowledge there is no report on the application of various cooking methods for culled ruminant meat particularly culled goat meat. Since culled goat from dairy goat farms is less utilized, it is important to understand the effect of heat treatment on culled meat characteristics to give the basic information for greater utilization of such animal species as an alternative meat source.

The goal of this research was to study the effect of boiling, grilling, and microwaving on the textural attributes-related properties of culled Saanen goat meat. The research was also conducted to see its lipid oxidation during refrigerated storage due to the possible variation in heating rate, heating medium, and oxidation processes involved among samples. The data obtained may be of benefit for further utilization of culled Saanen goat for meat consumption.

\section{Materials and methods}

\section{Materials}

Meat samples were collected from right and left parts of 5-year-old culled Thai Saanen crossbred goats $(85 \%$ Saanen goat $\times 12.5 \%$ Thai native). Biceps femoris and supraspinatus muscles were separated from the carcasses. Samples were cut into $2 \times 1.5 \times 1 \mathrm{~cm}^{3}$ chunks giving in total of 160 pieces from biceps fermoris and 128 pieces from supraspinatus, and then divided randomly into 4 parts including the control (raw meat) and heat treatment (boiling, grilling, and microwaving). The heating procedure for all heat treatments was regulated to reach an internal temperature of $85{ }^{\circ} \mathrm{C}$.

Samples from biceps femoris were used for physicochemical properties determination for a nonstorage study (proximate, total collagen, soluble collagen, cook loss, texture, color, and microstructure). Samples from supraspinatus were used for lipid oxidation evaluation (PV and TBARS). All pieces of the meat sample were placed in a plastic tray (polypropylene, square food container with lid, Aro ${ }^{B}$, Thailand). Twenty pieces/tray distributed for non-storage study (physicochemical analyses), while 8 pieces/tray were prepared for storage study (lipid oxidation). Each tray was then covered with its lid properly before being kept in a refrigerator at $4{ }^{\circ} \mathrm{C}$. The storage study was conducted for 5 days with 4 intervals $(0,1,3$, and 5 days of storage).

\section{Methods}

Proximate analysis

Proximate composition (moisture, protein, fat, and ash) was determined following guidelines explained in AOAC methods [10]. 
http://wjst.wu.ac.th

\section{Total collagen}

Total collagen was determined using the acid hydrolysis method [11]. Then, hydrolysed samples were used for hydroxyproline determination [12]. After that, the hydroxyproline content was converted into collagen ( $\mathrm{mg} / \mathrm{g}$ sample) by multiplying with 7.25 as a conversion factor.

\section{Soluble collagen}

Samples were extracted based on the procedure described by Liu et al. [13] with slight modification. The extraction solution was subjected to acid hydrolysis and hydroxyproline determination in the same manner as total collagen determination. Conversion of hydroxyproline was multiplied with 7.25 as a conversion factor. The soluble collagen was calculated and reported as a percentage of total collagen.

\section{Cook loss}

Cook loss was determined from sample weight before and after reaching an internal temperature of $85^{\circ} \mathrm{C}$. Cook loss was expressed in percentage of weight loss.

\section{Color}

Color was evaluated using a Hunterlab colorimeter (Hunterlab ColorFlex, Virginia). A standardization procedure was applied using black glass and white tile prior to color reading. Color was reported in lightness $\left(\mathrm{L}^{*}\right)$, redness $\left(\mathrm{a}^{*}\right)$, and yellowness $\left(\mathrm{b}^{*}\right)$ using the International Commission on Illumination (CIE) system.

\section{Texture}

Texture profile analysis (TPA) was applied to obtain texture characteristics of the sample. A texture analyser (TA-XTplus Stable Micro System Texture Analyser, UK) with its P35 probe and $50 \mathrm{~kg}$ load cell was fixed to determine hardness, springiness, cohesiveness, gumminess, and chewiness profiles. Typically, the instrument settings were as follows: pre-test speed: $2.00 \mathrm{~mm} / \mathrm{sec}$, test speed: $2.00 \mathrm{~mm} / \mathrm{sec}$, post-test speed: $10.00 \mathrm{~mm} / \mathrm{sec}$, target mode: strain, strain: $50 \%$, trigger type: auto (force), trigger force: $10.0 \mathrm{~g}$. Before sample analysis, a calibrating procedure was carried out as follows: calibration height: 20 , return speed: $15(\mathrm{~mm} / \mathrm{sec})$, contact force: $10(\mathrm{~g})$.

\section{Microstructure}

Microstructure evaluation of the sample [14] was carried out with a slight adaptation. A razor blade was used properly to obtain $1 \times 0.5 \times 0.5 \mathrm{~cm}^{3}$ meat specimen dimension during sample cutting. Glutaraldehyde (25\%) diluted in $0.1 \mathrm{M}$ phosphate buffer $\mathrm{pH} 6.8$ was used for specimen dipping for sample fixation. After $2 \mathrm{~h}$, the specimen was rinsed with distilled water. Then, a specimen dehydration sequence with 25, 50, 70, and $95 \%$ absolute ethanol was used. After that, 2 times dehydration using pure ethanol was then applied. Then, the specimen was cut into thin layers using a razor blade with assistance of short-dipping in cold nitrogen. A critical point drier (Polaron CPD7501, East Sussex, UK) was used to remove the remaining solution in the thin specimen. A sputter coater (West Chester, PA, USA) for gold coating process was used to complete sample preparation. A Scanning Electron Microscope (SEM) was used to obtain sample cross section and longitudinal photographs with $500 \times$ and $10.000 \times$ magnifications.

\section{Peroxide value (PV)}

PV was determined following the procedure explained by Richards and Hultin [15]. One gram of minced sample was transferred into a $50 \mathrm{ml}$ centrifugation tube and mixed with $11 \mathrm{ml}$ mixture of 2:1 choloroform:methanol for $1 \mathrm{~min}$ using a homogenizer (WiggenHauser ${ }^{\circledR}$, Germany). Then, addition of 2 $\mathrm{ml} 0.5 \% \mathrm{NaCl}$ was applied to the extract solution followed by mixing with a vortex. After that the mixture was centrifuged in a thermo electron centrifuge (Sorval Biofuge Primo R Centrifuge, Germany) at $3600 \times \mathrm{g} / 3 \mathrm{~min}$. Two separate layers formed. Then, $3 \mathrm{ml}$ of lower layer was collected and transferred into a glass tube in which $2 \mathrm{ml}$ of 2:1 choloroform:methanol had already been added. Subsequently, $25 \mu 1$ 
http://wjst.wu.ac.th

ammonium thiocyanate was added and vortexed. Then, the procedure continued with addition of $25 \mu 1$ iron(II) chloride and vortex stirring. A standard curve was prepared from cumene hydroxyproline. Absorbance of the samples was read at $500 \mathrm{~nm}$ using a spectrophotometer (Libra S22 Biochrom, England). The absorbance was recorded and reported in $\mathrm{mg}$ hydroperoxide $/ \mathrm{kg}$ meat sample.

\section{Thiobarbituric acid reactive substances (TBARS)}

TBARS was evaluated based on the adapted method of Buege and Aust [16]. One gram of minced sample was transferred into a glass tube containing $5 \mathrm{ml}$ TCA-TBA-HCl reagent made from $15 \%$ of TCA, $0.375 \% \mathrm{TBA}$, and $0.25 \mathrm{~N} \mathrm{HCl}$. It was heated for 10 min followed by cooling under running tap water. Then, the supernatant was filtered using Whatman paper number 1. After that, the filtrate was spectophotometrically measured at $535 \mathrm{~nm}$ with the use of 1,1,3,3-tetramethoxypropane as a standard. The result was reported as mg malonaldehyde/ $\mathrm{kg}$ meat sample.

\section{Statistical analysis}

The research was carried out using a Completely Randomized Design (CRD). Data were statistically analyzed using the SPSS Statistics program. Comparison means were determined using One-Way ANOVA. Significance (0.05) of post hoc multiple comparisons conveyed using Duncan's Multiple Range Test.

\section{Results and discussion}

\section{Physicochemical characteristics}

\section{Chemical composition}

The chemical composition of culled Thai Saanen goat meat treated with various heating methods are presented in Table 1. The microwaved sample exhibited higher moisture content than those of boiled and grilled samples $(\mathrm{P}<0.05)$, while lower protein and fat content were obtained $(\mathrm{P}<0.05)$. The boiled sample revealed higher fat content and lower ash content than the other heated samples $(\mathrm{P}<0.05)$. Grilled samples exhibited higher ash content than other samples $(\mathrm{P}<0.05)$. As for collagen composition, the grilled sample exhibited higher total collagen than boiled and microwaved samples $(\mathrm{P}<0.05)$. On the other hand, the microwaved sample exhibited higher soluble collagen percentage than the others $(\mathrm{P}<$ 0.05). From those proximate and collagen compositions, boiled and grilled samples commonly had more chemical alterations compared to raw meat (control).

Faster heating rate is a characteristic of microwave heating compared to conventional cooking [17]. Thus, less moisture loss in the microwaved sample compared to other cooking methods is associated with its faster rate to reach equal end point temperature compared to the boiled and grilled processes. Higher moisture loss in boiled and grilled samples resulted in increasing percentages of protein and fat. Moreover, the grilled method imparted lower fat percentage compared to the boiled sample due to more fat melting. As a result of heat-induced denaturation of myoglobin, diluted mineral content (particularly iron from myoglobin) caused a decreasing percentage of ash content in the boiled sample. This is in agreement with another report indicating that soluble haem and insoluble haem iron might lost as myoglobin denatures, while soluble and insoluble non-haem iron accumulates in the juice during cooking [18]. 
http://wjst.wu.ac.th

Table 1 Chemical composition of culled Saanen crossbred goat meat treated with various heating methods.

\begin{tabular}{lcccc}
\hline Chemical composition & Raw & Boil & Grill & Microwave \\
\hline Proximate ( $\mathrm{n}=3)$ & & & & \\
Moisture (\%) & $77.47 \pm 0.12^{\mathrm{a}}$ & $63.04 \pm 0.21^{\mathrm{d}}$ & $63.89 \pm 0.10^{\mathrm{c}}$ & $68.03 \pm 0.08^{\mathrm{b}}$ \\
Protein (\%) & $18.93 \pm 0.29^{\mathrm{c}}$ & $29.20 \pm 0.47^{\mathrm{a}}$ & $29.59 \pm 0.30^{\mathrm{a}}$ & $26.72 \pm 0.11^{\mathrm{b}}$ \\
Fat (\%) & $2.78 \pm 0.29^{\mathrm{c}}$ & $5.98 \pm 0.03^{\mathrm{a}}$ & $4.01 \pm 0.06^{\mathrm{b}}$ & $2.95 \pm 0.06^{\mathrm{c}}$ \\
Ash (\%) & $1.06 \pm 0.04^{\mathrm{c}}$ & $0.93 \pm 0.04^{\mathrm{d}}$ & $1.48 \pm 0.09^{\mathrm{a}}$ & $1.23 \pm 0.02^{\mathrm{b}}$ \\
Collagen (n=4) & & & \\
Total collagen (mg/g) & $9.55 \pm 0.11^{\mathrm{c}}$ & $12.85 \pm 0.33^{\mathrm{b}}$ & $14.35 \pm 0.82^{\mathrm{a}}$ & $10.52 \pm 0.17^{\mathrm{c}}$ \\
Soluble collagen (\%) & $3.16 \pm 1.27^{\mathrm{b}}$ & $2.74 \pm 1.58^{\mathrm{b}}$ & $3.45 \pm 0.58^{\mathrm{b}}$ & $6.57 \pm 0.68^{\mathrm{a}}$ \\
\hline
\end{tabular}

${ }^{\text {abcd }}$ Means $( \pm \mathrm{SD})$ within a row with different letters differ significantly $(\mathrm{P}<0.05)$.

Moisture loss also caused an increase in collagen in the boiled and grilled samples. This was due to similar phenomenon obtained in protein and fat contents. Microwave heating is likely to cause more solubilization of the collagen. This is in agreement with previous work which noted a similar phenomenon of higher soluble collagen formation via microwave heating compared to conventional heating [19]. Electromagnetic-to-thermal energy conversion is a basic concept of microwave heating. Water molecules and ionic components of meat absorb the energy by rotation and translation, respectively [1]. A difference with surface heating commonly occurs in conventional cooking whereas heat energy of the microwave method is produced internally in the sample [20], and thus may solubilize more collagen in the interior of the meat. Moreover, another assumption as related to less solubilized collagen released together with fluid during microwaving might be proposed. This is concomitant with the result of cook loss (Figure 1).

\section{Cook loss}

The cook loss of culled Thai Saanen goat meat under various heating methods is presented in Figure 1. Microwaved samples exhibited lower cook loss than the other methods $(P<0.05)$, while there was no significant difference observed between the boiled and grilled samples $(\mathrm{P} \geq 0.05)$. The longer heating rate needed for the boiling and grilling processes to reach an equal end point temperature to that of the microwave process is caused by more dripping. Additionally, the release of fluid during cooking not only is due to moisture loss but also from fat melting.

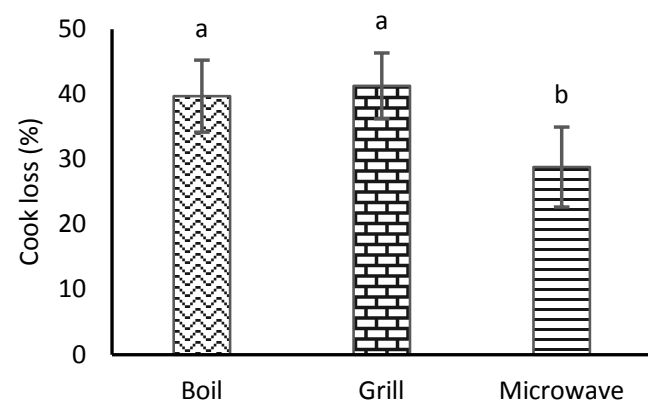

Figure 1 Cook loss of culled Saanen crossbred goat meat treated with various heating methods. ${ }^{\text {ab }}$ Means $( \pm \mathrm{SD})$ with different letters differ significantly $(\mathrm{P}<0.05) ;(\mathrm{n}=10)$. 
http://wjst.wu.ac.th

As documented by other authors, water releasing and fat melting are common during cooking. This is caused by uncoiling, reuniting, or coagulating of peptide chains of muscle protein [21]. Moreover, even though the loss of moisture between boiled and grilled samples was comparable, melted fat in the grilled sample might significantly occur to a greater extent as elucidated by lower fat content (Table 1).

Physical shrinkage in heated meat is associated with the release of liquid from meat sample. This is due to the loss of nature states of myofibrillar proteins and connective tissue [22]. Cooking loss is associated with myofibrillar proteins denaturation, collagen shrinkage, and sarcomere shortening. Thus, water holding capacity decreased once myosin denatured and actomyosin dehydrated [14].

\section{Color}

Color $\left(\mathrm{L}^{*}, \mathrm{a}^{*}, \mathrm{~b}^{*}\right)$ of culled Thai Saanen goat meat treated with various heating methods is described in Figure 2. The boiled sample exhibited higher lightness than that of the grilled and microwaved samples $(\mathrm{P}<0.05)$, while lower redness and yellowness were obtained $(\mathrm{P}<0.05)$. Microwaved sample revealed higher lightness than that of the grilled sample $(\mathrm{P}<0.05)$, while the results in redness and yellowness of the 2 heating methods were not different $(\mathrm{P} \geq 0.05)$. In general, heated samples showed increasing results in lightness and yellowness as well as decreasing result in redness compared to the raw sample (control).

Higher lightness in the boiled sample might be associated with opaque-white color of denatured myofibrillar protein. This contributed to coagulation of the fibre protein (particularly myosin) during heating [23]. Myoglobin denaturation decreased redness of all heated samples. Water as a heating medium accelerated more myoglobin release from the boiled sample and thus resulted in significantly less redness. As related to myoglobin denaturation in cooked meat, the dull-brown color is due to denatured globin hemichrome [24]. Then, a combination of such color and white-coagulated fibre protein reflected the higher yellowness formation in the grilled and microwaved samples.
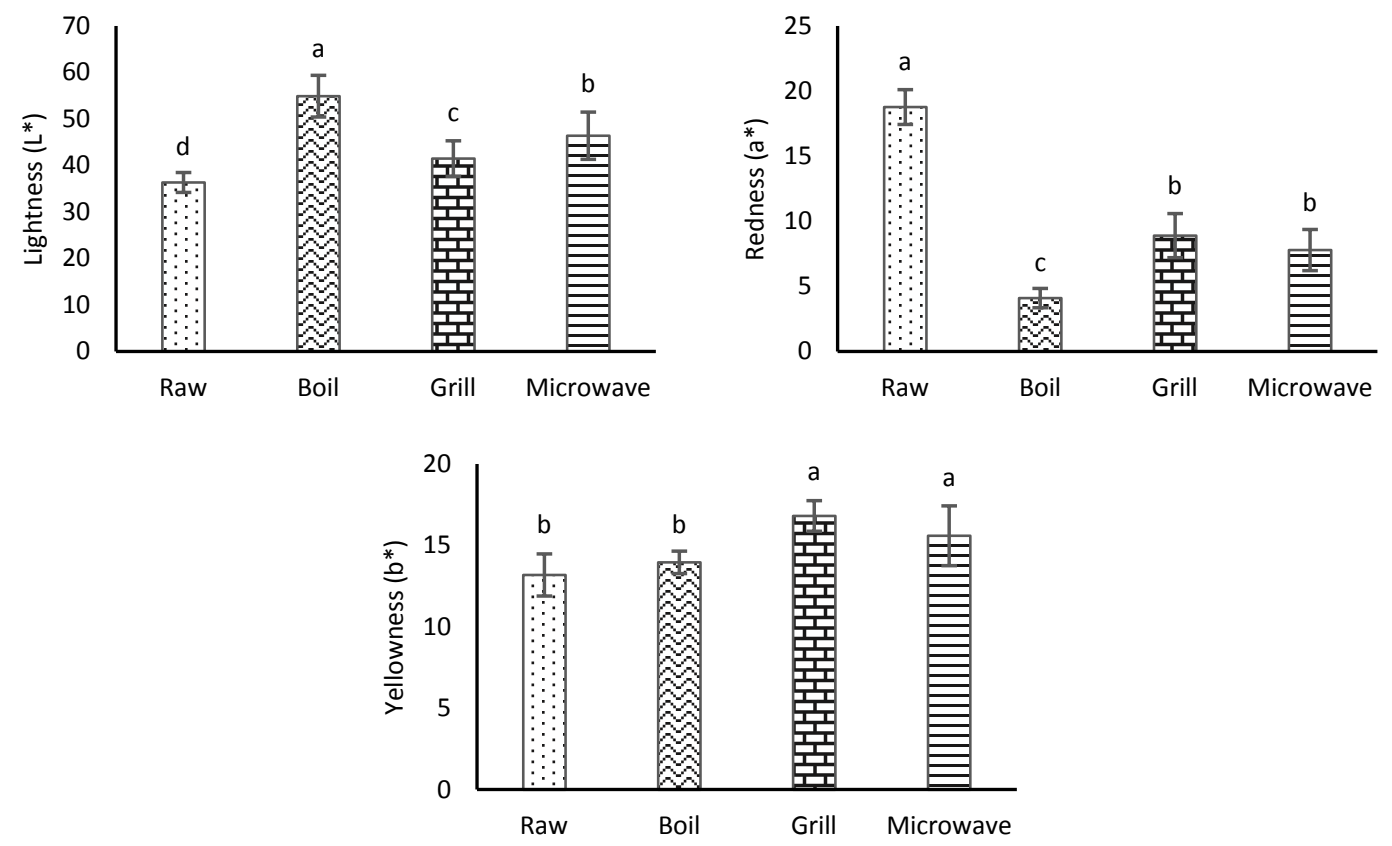

Figure 2 Color $\left(\mathrm{L}^{*}, \mathrm{a}^{*}, \mathrm{~b}^{*}\right)$ of culled Saanen crossbred goat meat treated with various heating methods. ${ }^{\text {abcd }}$ Means $( \pm \mathrm{SD})$ with different letters differ significantly $(\mathrm{P}<0.05) ;(\mathrm{n}=10)$. 
http://wjst.wu.ac.th

Grilling the sample visually generated brown color as reflected in its lower lightness, higher redness, and higher yellowness in instrumental analysis. This might be associated with the higher temperature on meat surface during grilling. The Maillard reaction was generated particularly on the meat surface during heating. Even though it was regulated to reach internal temperature of $85{ }^{\circ} \mathrm{C}$, the meat surface was exposed to higher temperature due to the setting of the grill above $200{ }^{\circ} \mathrm{C}$.

As explained by other authors, the amino acid reacts with reducing sugar when the heating temperature is higher than $110^{\circ} \mathrm{C}$. This reaction generates a brownish color on the meat surface during dry heating [1]. Related to this present study, dehydration of the meat surface is due to the effect of grilling providing the optimal conditions for the Maillard reaction to cause browning. Due to browning level that is usually used as a standard of cooked meat, the color of the grilled sample might be more preferable.

\section{Texture}

The texture (TPA) of culled Thai Saanen goat meat treated with various heating methods is provided in Figure 3. The grilled sample revealed higher hardness, gumminess, and chewiness than those from boiled and microwaved samples $(\mathrm{P}<0.05)$, while boiled and microwaved samples exhibited comparable results for these textural properties $(\mathrm{P} \geq 0.05)$. Moreover, there was no significant difference obtained in springiness and cohesiveness $(\mathrm{P} \geq 0.05)$. At the same time, these heat treatments had lower hardness and springiness than those of the raw sample (control), while higher cohesiveness was performed.

Collagen and myofibrillar protein are 2 important meat proteins determining meat texture. In fact, collagen hydrolysis led to meat softening while myofibrillar denaturation led to meat hardening. Moreover, cooked samples in this study obtained less hardness compared to the raw sample which might be due to the greater effect of structural changes of collagen within the muscle.

Continuous alteration of endomysium and perimysium due to cooking ruptures the myofibrillar structural integrity. When collagen in endomysium softens, fibres continue to be ruptured, gradually weakening linkages between them, resulting in a tenderizing effect on cooked meat [25]. In agreement with this present study, other researchers also found that cooked meat of the Holstein breed had lower shear force compared to that of raw meat (50.4 vs $52.6 \mathrm{~N} / \mathrm{cm}^{2}$ ) [26].

The existence of water as a heat medium probably helped the changes in structural collagen in the boiled sample into solubilized collagen. Less remaining collagen did not directly mean that boiling imparted a small percentage of solubilized collagen compared to that of grilling. Some solubilized collagen might be dissolved into water and thus decreased the remaining soluble collagen percentage (Table 1). This finally resulted in a lower hardness level even though partial hardening of myofibrillar protein was presumed to still occur.

Lower hardness, gumminess, and chewiness in the microwaved sample might be correlated to more soluble collagen during heating (Table 1). Lesser myofibrillar hardening might be obtained in the microwaved sample due to its faster heating rate. In agreement with this present study, another report also noted that short microwave heating resulted in a softening effect on connective tissue, while myofibrillar protein functionality was preserved [27].

Crushed surface formation commonly occurs during grilling while moist and rare conditions in the internal layer are preserved [28]. Thus, this crush formation generates higher hardness of the grilled sample than other heated samples. Moreover, the more compact structure in the grilled sample might be associated with lower moisture and higher collagen content. Comparable moisture and protein contents between boiled and grilled samples were observed. However, lower fat content in the grilled sample might be due to its higher hardness. Thus, this led to lower results in gumminess and chewiness. An author explained that fat contributes an essential consequence on the textural attributes of meat. Tough and dry characteristics might be the result of removal of fat from the product [29]. 


\section{http://wjst.wu.ac.th}
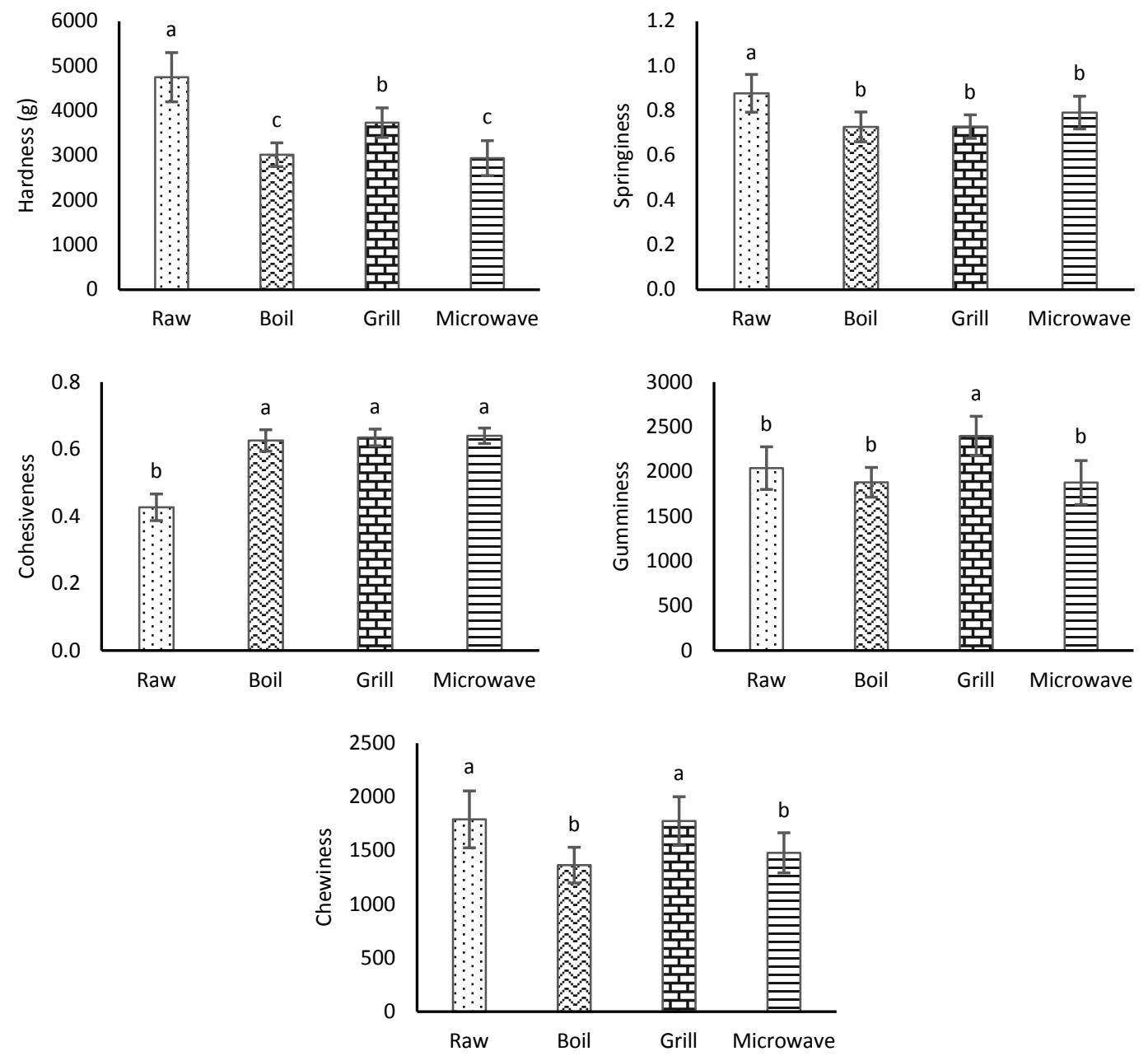

Figure 3 TPA of culled Saanen crossbred goat meat treated with various heating methods. ${ }^{\text {abc }}$ Means $( \pm \mathrm{SD})$ with different letters differ significantly $(\mathrm{P}<0.05) ;(\mathrm{n}=10)$.

\section{Microstructure}

The microstructure of culled Thai Saanen goat meat treated with various heating methods and its fibre diameter and sarcomere length are revealed in Figures 4 and 5, respectively. Fibre diameter of all heated samples was significantly lower than that of raw samples $(\mathrm{P}<0.05)$. However, no significant difference among heated samples was observed $(\mathrm{P} \geq 0.05)$. At the same time, lower sarcomere length was also found in all heated samples compared to the raw sample. Among the heated samples, the boiled sample had lower sarcomere length, followed by the grilled and microwaved samples $(\mathrm{P}<0.05)$.

Temperature is significant in the shrinkage of fibre diameter. Increasing the temperature caused more meat fibre shrinkage [30]. Sarcomere shortening is also heat induced-dependent. Moreover, heat induced treatment might give more effect on sarcomere shortening compared to fibre diameter shrinkage [14]. 

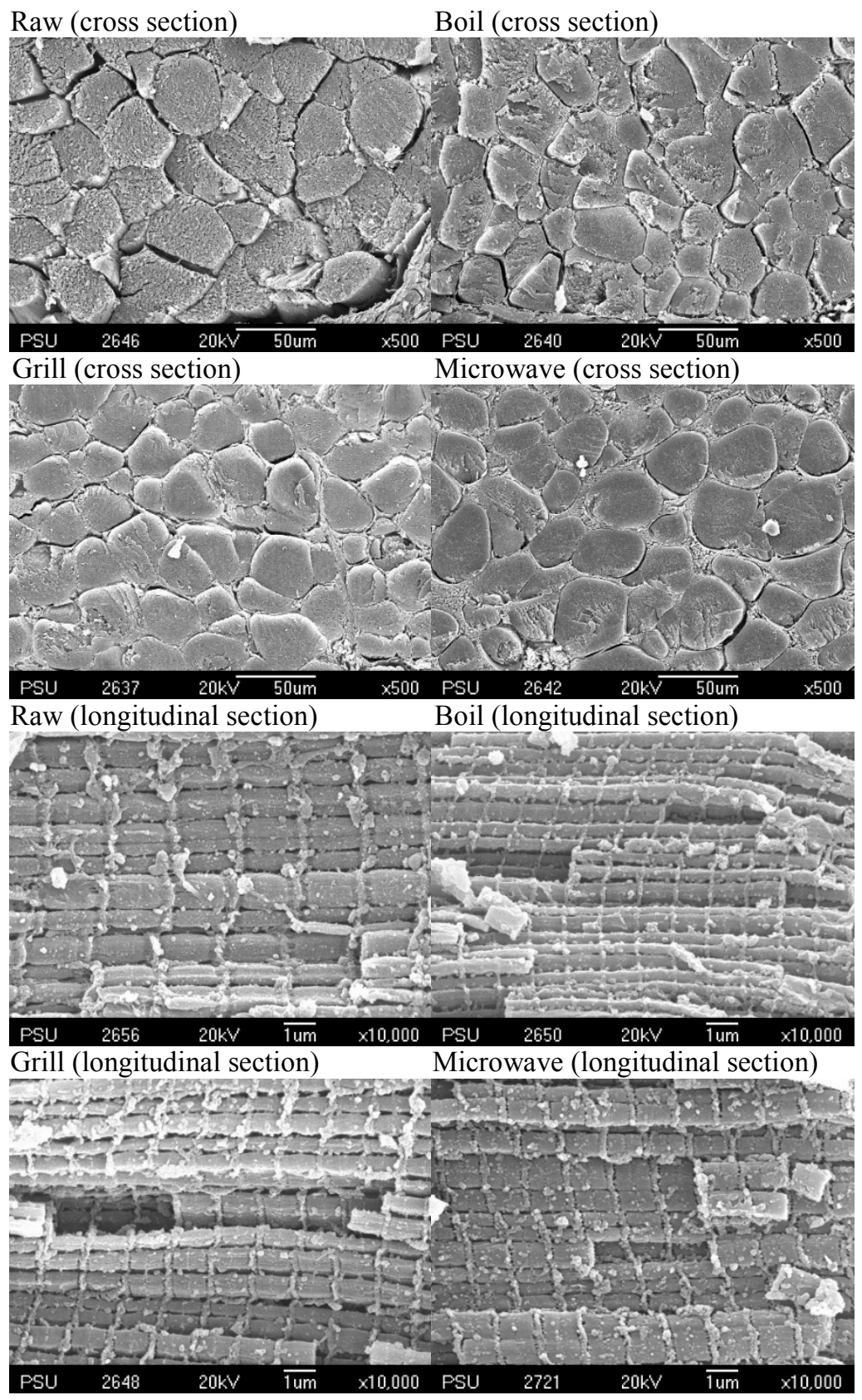

Figure 4 SEM micrographs of cross and longitudinal sections of culled Saanen crossbred goat meat (bicep femoris) treated with various heating methods and its fibre diameter and sarcomere lengths. 
http://wjst.wu.ac.th
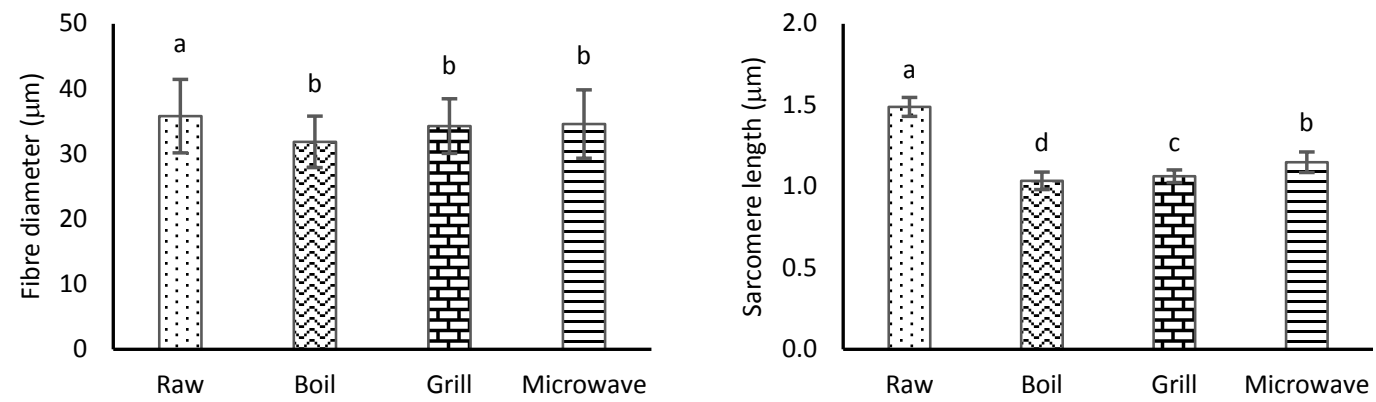

Figure 5 Fibre diameter and sarcomere length of culled Saanen crossbred goat meat (bicep femoris) treated with various heating methods and its fibre diameter and sarcomere lengths. ${ }^{\text {abc }}$ Means $( \pm$ SD) with different letters differ significantly $(\mathrm{P}<0.05) ;(\mathrm{n}=60)$.

Sarcomere shortening between temperatures of $60-80{ }^{\circ} \mathrm{C}$ was observed. A slight change was recorded around $60{ }^{\circ} \mathrm{C}$. Moreover, a gradual sarcomere shortening until $80{ }^{\circ} \mathrm{C}$ was observed [31]. In this study, boiling to reach temperature $85^{\circ} \mathrm{C}$ caused more shrinkage in the longitudinal alignment of muscle fibre probably due to the longer cooking time. This could be attributed to reduced size of the meat after boiling compared to other methods.

\section{Lipid oxidation}

The results of PV and TBARS of cooked culled Thai Saanen goat meat treated with various heating methods during refrigerated storage are presented in Figure 6. The boiled sample exhibited higher PV before storage compared to others, but the grilled sample revealed a sharper increase until 5 days of storage $(\mathrm{P}<0.05)$. The grilled sample exhibited a higher TBARS before storage compared to others, but a sharper increase in TBARS formation in the boiled sample was observed $(\mathrm{P}<0.05)$.

Iron, in the form of bound or free-heme protein, is widely known as the main non-enzymatic catalyst inducing lipid peroxidation [32,33]. Higher PV in the boiled sample might be due to the more iron released from myoglobin. Water as the heating medium in such a sample causes free iron to be more easily moved and used as a catalyst for peroxide formation during cooking. Higher mobilized catalysts due to higher water activity $(0.55-0.85)$ led to elevated degrees of lipid oxidation [34]. Thus, a combination of thermally denatured protein and free iron significantly accelerated lipid oxidation [35]. This phenomenon was in agreement with previous research which proved the release of non-heme iron from bound heme pigment $(<10 \%)$ due to the effect of cooking [36].

A sharper increase in the PV in the grilled sample was due to its dominant peroxide formation until 5 days of storage, while more primary oxidation products in the boiled sample were converted into malonaldehyde as could be seen in TBARS formation. A structurally tender and looser texture in the boiled sample compared to the grilled sample might allow acceleration of the reaction of lipid oxidation products responsible for higher TBARS formation during storage. 
http://wjst.wu.ac.th
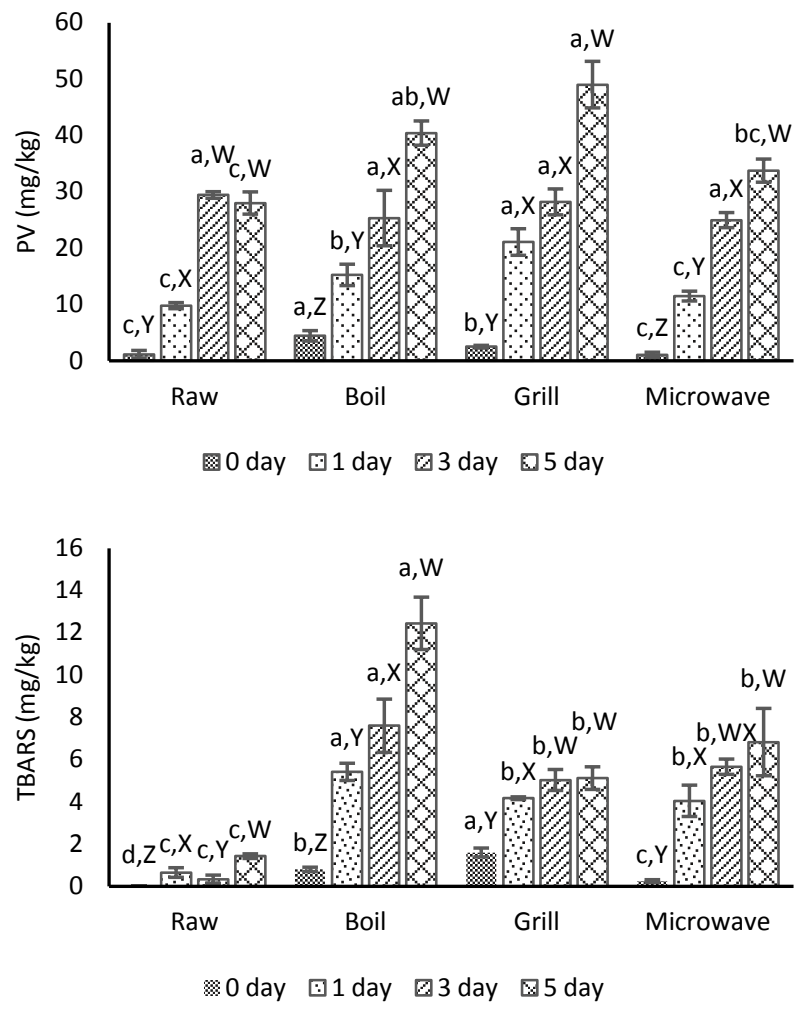

Figure $6 \mathrm{PV}$ and TBARS of culled Saanen crossbred goat meat treated with various heating methods during refrigerated storage. ${ }^{\text {abcd }}$ Means $( \pm \mathrm{SD})$ within various heating methods with different lower cases differ significantly $(\mathrm{P}<0.05)$. ${ }^{\text {WXYZ }}$ Means $( \pm \mathrm{SD})$ within various storage periods with different upper cases differ significantly $(\mathrm{P}<0.05) ;(\mathrm{n}=4)$.

\section{Conclusions}

Variation in heating rate to reach $85^{\circ} \mathrm{C}$ end point temperature caused variation in moisture loss. Thus, this affected the remaining total solid of the sample. In general, higher moisture loss resulted in higher percentage of total solid fractions. In the case of collagen, some part of the soluble collagen might be lost together with the fluid (juice) during cooking. The higher moisture loss as well as less remaining soluble collagen resulted in higher hardness, gumminess, and chewiness in the grilled sample. Browning due to the Maillard reaction reflected a more attractive cooked color in the grilled sample. As compared to others, microwave cooking seemed to generate some specific physical expectation on meat as reflected from its sufficient tenderness, less cooking loss, and less shrinkage. Thus, the microwaving method imparts less shrinkage of sample dimensions without excluding its tenderizing effect compared to boiling and grilling. The grilled sample was less stable toward peroxide formation, while the boiled sample was less stable toward TBARS formation. Cooking via grilling and microwaving could be used as other options to replace the common boiling applied for goat meat. Moreover, microwaving could be a good alternative cooking method to give comparable results to boiling in textural properties of Saanen goat meat due its higher solubilized collagen content. The lower lipid oxidation of the microwaved sample during storage was also observed during refrigerated conditions. 
http://wjst.wu.ac.th

\section{Acknowledgements}

The authors acknowledge research fund provided by Prince of Songkla University under research project No. AGR581130S-0. The first author would also like to thank the Ministry of Research, Technology and Higher Education of the Republic of Indonesia for scholarship provided during his study.

\section{References}

[1] C Bejerholm, MA Tørngren and MD Aaslyng. Cooking of Meat. In: M Dikeman and C Devide (eds.). Encyclopedia of Meat Sciences. Vol I. $2^{\text {nd }}$ ed. Academic Press, London, 2014, p. 370-76.

[2] F Liu, L Meng, X Gao, X Li, H Luo and R Dai. Effect of end point temperature on cooking losses, shear force, color, protein solubility and microstructure of goat meat. J. Food Process. Pres. 2013; 37, 275-83.

[3] JM James and CR Calkins. The influence of cooking rate and holding time on beef chuck and round flavour. Meat Sci. 2008; 78, 429-37.

[4] C Vasanthi, V Venkataramanujam and K Dushyanthan. Effect of cooking temperature and time on the physico-chemical, histological and sensory properties of female carabeef (buffalo) meat. Meat Sci. 2007; 76, 274-80.

[5] R Domínguez, M Gómez, S Fonseca and JM Lorenzo. Effect of different cooking methods on lipid oxidation and formation of volatile compounds in foal meat. Meat Sci. 2014; 97, 223-30.

[6] T Dzudie, R Ndjouenkeu and A Okubanjo. Effect of cooking methods and rigor state on the composition, tenderness and eating quality of cured goat loins. J. Food Eng. 2000; 44, 149-53.

[7] MS Yarmand and A Homayouni. Effect of microwave cooking on the microstructure and quality of meat in goat and lamb. Food Chem. 2009; 112, 782-85.

[8] MM Campo, E Muela, JL Olleta, LA Moreno, AM Santaliestra-Pasías, MI Mesana and C Sanñudo. Influence of cooking method on the nutrient composition of Spanish light lamb. J. Food Comp. Anal. 2013; 31, 185-90.

[9] M Roldán, T Antequera, T Pérez-Palacios and J Ruiz. Effect of added phosphate and type of cooking method on physico-chemical and sensory features of cooked lamb loins. Meat Sci. 2014; 97, 69-75.

[10] AOAC. Official Methods of Analysis. $17^{\text {th }}$ ed. Association of Official Analytical Chemists, Washington DC, 2000.

[11] K Palka. Changes in intramuscular connective tissue and collagen solubility of bovine $m$. semitendinosus during retorting. Meat Sci. 1999; 53, 189-94.

[12] I Bergman and R Loxley. Two improved simplified methods for the spectrophotometric determination of hydroxyproline. Anal. Chem.1963; 35, 1961-65.

[13] A Liu, T Nishimura and K Takahashi. Relationship between structural properties of intramuscular connective tissue and toughness of various chicken skeletal. Meat Sci. 1996; 43, 43-49.

[14] K Palka and H Daun. Changes in texture, cooking losses, and myofibrillar structure of bovine $M$. semitendinosus during heating. Meat Sci. 1999; 51, 237-43.

[15] MP Richards and HO Hultin. Contribution of blood and blood components to lipid oxidation in fish muscle. J. Agr. Food Chem. 2002; 50, 555-64.

[16] JA Buege and SD Aust. Microsomal lipid peroxidation. Meth. Enzymol. 1978; 52, 302-10.

[17] R Vadivambal and DS Jayas. Non-uniform temperature distribution during microwave heating of food materials: A review. Food Bioprocess Tech. 2010; 3, 161-71.

[18] RW Purchas, DC Simcock, TW Knight and BHP Wilkinson. Variation in the form of iron in beef and lamb meat and losses of iron during cooking and storage. Int. J. Food Sci. Tech. 2003; 38, 82737.

[19] JF Zayas and JO Naewbanij. The influence of microwave heating on the textural properties of meat and collagen solubilization. J. Food Process. Pres. 1986; 10, 203-14. 
http://wjst.wu.ac.th

[20] BK Tiwari and C O'Donnell. Thermal Processing of Meat and Meat Products. In: DW Sun (ed.). Thermal Food Processing: New Technology and Quality Issues. $2^{\text {nd }}$ ed. CRC Press, Boca Raton, 2012, p. 195-220.

[21] VA Vaclavik and EW Christian. Essentials of Food Science. $4^{\text {th }}$ ed. Springer, New York, 2014.

[22] NP Brunton, JG Lyng, L Zhang and JC Jacquier. The use of dielectric properties and other physical analyses for assessing protein denaturation in beef biceps femoris muscle during cooking from 5 to $85^{\circ} \mathrm{C}$. Meat Sci. 2006; 72, 236-44.

[23] H McGee. On Food and Cooking: The Science and Lore of Kitchen. Completely revised and updated. Scribner, New York, 2004.

[24] SP Suman and P Joseph. Color and Pigment. In: M Dikeman and C Devine (eds.). Encyclopedia of Meat Sciences. Vol 1. $2^{\text {nd }}$ ed. Academic Press, London, 2014, p. 244-51.

[25] NN Terra, RML de Campos and PCB Campagnol. Sensory Aspects of Cooked Meats. In: LML Nollet and F Toldrá (eds.). Sensory Analysis of Foods of Animal Origin. CRC Press, Boca Raton, 2011, p. 87-98.

[26] M Christensen, P Ertbjerg, S Failla, C Sañudo, RI Richardson, GR Nute, JL Olleta, B Panea, P Albertí, M Juárez, JF Hocquette and JL Williams. Relationship between collagen characteristics, lipid content and raw and cooked texture of meat from young bulls of fifteen European breeds. Meat Sci. 2011; 87, 61-5.

[27] T Varzakas, A Mahn, C Pérez, M Miranda and H Barrientos. Blanching. In: T Varzakas and C Tzia (eds.). Handbook of Food Processing: Food Preservation. CRC Press, Boca Raton, 2016, p. 1-26.

[28] A Schloss and D Joachim. Mastering the Grill. Chronicle Books, California, 2007.

[29] KB Harris. Nutrient Claims on Packaging. In: M Dikeman and C Devine (eds.). Encyclopedia of Meat Sciences. Vol 2. $2^{\text {nd }}$ ed. Academic Press, London, 2014, p. 449-54.

[30] CB Li, GH Zhou and XL Xu. Dynamical changes of beef intramuscular connective tissue and muscle fiber during heating and their effects on beef shear Force. Food Bioprocess Tech. 2010; 3, $521-7$.

[31] J Lepetit, A Grajales and R Favier. Modelling the effect of sarcomere length on collagen thermal shortening in cooked meat: consequence on meat toughness. Meat Sci. 2000; 54, 239-50.

[32] JP Baron and HJ Andersen. Myoglobin-induced lipid oxidation: A review. J. Agric. Food Chem. 2002; 50, 3887-97.

[33] B Min and DU Ahn. Mechanism of lipid peroxidation in meat and meat products: A review. Food Sci. Biotechnol. 2005; 14, 152-63.

[34] WW Nawar. Biochemical Processes: Lipid Instability. In: IA Taub and RP Singh (eds.). Food Storage Stability. CRC Press, Boca Raton, 1998, p. 98-103.

[35] EN Frankel. Lipid Oxidation. $2^{\text {nd }}$ ed. Woodhead Publishing Limited, Cambridge, 2012.

[36] JO Igene, JA King, AM Pearson and JI Gray. Influence of heme pigments, nitrite, and non-heme iron on development of warmed-over flavor (WOF) in cooked meat. J. Agric. Food Chem. 1979; 27, $838-42$. 